\title{
A novel mutation in SLC37A4 gene in a Sri Lankan boy with glycogen storage disease type Ib associated with very early onset neutropenia
}

\author{
Vajira HW Dissanayake $^{1,2, *}$, Jayan D Jayasinghe ${ }^{1}$, Viranga Tilakaratna ${ }^{2}$, Rohan W Jayasekara ${ }^{1}$ \\ ${ }^{1}$ Human Genetics Unit, Faculty of Medicine, University of Colombo, Sri Lanka, ${ }^{2}$ Asiri Centre for Genomic and \\ Regenerative Medicine, Asiri Surgical Hospital, Colombo, Sri Lanka
}

*Correspondence to: Vajira Dissanayake, Email: vajirahwd@hotmail.com, Tel: +94 777351835, Fax: +94 112689979

Received 26 March 2011, Accepted 05 April 2011, Published online 18 May 2011

J Mol Genet Med, 2010, Vol 5, 262-263

(C) Copyright The Authors: This is an open access article, published under the terms of the Creative Commons Attribution Non-Commercial License (http://creativecommons.org/licenses/by-nc/2.0/uk/). This license permits noncommercial use, distribution and reproduction of the article, provided the original work is appropriately acknowledged with correct citation details.

\begin{abstract}
Glycogen storage disease type Ib (GSD Ib) [MIM 232220] is caused by mutations in the gene encoding microsomal glucose-6-phosphate translocase (G6PT) (Veiga-DaCunha et al, 1998). This solute carrier family 37, member 4 gene (SLC37A4) is located on chromosome 11q23.3 and encodes a 429 amino acid polypeptide (Veiga-Da-Cunha et al, 1998). This protein transports glucose-6-phosphate into the endoplasmic reticulum, where the enzyme glucose-6-phosphatase converts glucose-6-phosphate into glucose and inorganic phosphate. Mutations in SLC37A4 result in accumulation of glucose-6-phosphate in cells. The SLC37A4 gene has 9 exons and so far 83 mutations have been reported (Human Gene Mutation Database, 2011). Here, we report the identification of a novel mutation in the SLC37A4 gene in a Sri Lankan child and the associated clinical phenotype.
\end{abstract}

This child was a three month old baby boy - the first child born to a consanguineous Sinhalese couple. The child had had pyrexia and umbilical sepsis few days after birth and recurrent, generalized pustular skin eruptions on and off since then. His abdomen was protruding. He had had persistent neutropenia, confirmed by haematological tests from the age of 3 weeks. Physical examination showed a grossly enlarged liver. He weighed $5.8 \mathrm{Kg}$ (Birth weight: $3.6 \mathrm{Kg}$ ). The weight was within the 50 th percentile.

Investigation findings were as follows: Fasting blood glucose: $66 \mathrm{mg} / \mathrm{dl}$ (reference interval: 65-110mg/dl); plasma lactate: $89.8 \mathrm{mg} / \mathrm{dl}$ (reference interval: 4.5 $19.8 \mathrm{mg} / \mathrm{dl}$ ); serum uric acid: $8.54 \mathrm{mg} / \mathrm{dl}$ (reference interval: 2.4-7.0mg/dl); serum triglycerides: $1236 \mathrm{mg} / \mathrm{dl}$ (reference interval: $10-200 \mathrm{mg} / \mathrm{dl}$ ); serum cholesterol: $242 \mathrm{mg} / \mathrm{dl}$ (reference interval: 140-239 mg/dl); Alanine transaminase (ALT): 225.3U/1 (reference interval: <40U/1); Aspartate transaminase (AST): 566.5U/1 (reference interval: <40U/1),
Alkaline phosphetase: 795.5U/1 (reference interval: 98279U/1) and Gamma glutaryl transferase: 960.1U/1 (reference interval: 7-50U/1).

The neutrophil count in the peripheral blood was frequently fluctuating between $0.2 \times 10^{3} / \mu 1$ and $0.9 \times 10^{3} / \mu 1$ (reference interval: $1.5-9.0 \times 10^{3} / \mu \mathrm{l}$ ) throughout this period. Bone marrow biopsy and peripheral blood picture were otherwise normal except for the low neutrophil counts. Based on the above clinical and laboratory findings, a clinical diagnosis of GSD type I was determined. First mutation analysis of the glucose-6-phosphatase (G6PC) gene was undertaken to confirm/exclude GSD Ia. No mutations were found in the G6PC gene. This was followed by screening for mutations in SLC37A4 gene to confirm/exclude GSD Ib. Genetic testing in both instances was done after obtaining written informed consent from the parents. Genomic DNA was extracted from the child's peripheral venous blood. All the exons and intron-exon boundaries of the G6PC and SLC37A4 genes were analyzed. Direct sequencing of PCR products was performed on both forward and reverse strands using the same primers for PCR. Cycle sequencing was performed with a BigDye Terminator Cycle Sequencing Ready Reaction kit (Applied Biosystems, Foster City, CA, USA). The sequence was read following capillary electrophoresis on an ABI 3130 Genetic Analyzer (Applied Biosystems). The sequence was compared with the reference sequence (NG_013331.1 RefSeqGene) in the National Center for Biotechnology Information database (http://www.ncbi.nlm.nih.gov). Detailed methods can be provided on request.

Sequence analysis showed that codon 50 of the SLC37A4 gene was converted from GGG to GAG by the substitution of a Guanine nucleotide by an Adenine nucleotide (Figure 1). 
This results in the substitution of Glyceine (G) by Glutemic acid (E) in the amino acid sequence of the G6PT protein [p.G50E].

GSD type I or von Gierke disease includes a clinically, biochemically, and genetically heterogeneous group of autosomal recessive disorders. The basic defects reside in the impairment of the terminal steps of glycogenolysis and gluconeogenesis, at different levels. Mutations of the G6PC gene are responsible for the most frequent form of GSD type I, the subtype Ia. In GSD Ia, the white blood cell count is generally within reference ranges because leukocyte function is unaffected by the defect. In contrast, chronic neutropenia due to impaired function of neutrophils, is found in GSD Ib (Visser et al, 2000). The clinical manifestations of GSD type I include growth retardation, hepatomegaly, hypoglycemia, lactic acidemia, hyperuricemia, and hyperlipidemia. In addition, patients with GSD Ib commonly have infectious complications which are caused by neutropenia and dysfunction of neutrophils. The diagnosis of GSD type I is based on its clinical presentation; i.e., abnormal plasma concentrations of glucose, lactate, uric acid, triglycerides, lipids; liver biopsy to measure enzyme activity; and molecular genetic testing (Visser et al, 2000).

This child had all the clinical and biochemical parameters suggestive of GSD Ia, except persistent neutropenia. Individuals with GSD Ia who are homozygous for the p.G188R mutation in the G6PC gene have been reported with GSD Ib like phenotype with neutropaenia (Weston et al, 2000). This child was tested for mutations in the G6PC gene to exclude this possibility. In untreated patients with GSD Ib, neutropenia usually manifests after about 1 year of age (Weston et al, 2000). In this child however, neutrophils were significantly reduced, with recurrent skin sepsis almost from birth.

In summary, we identified a missence mutation in the SLC37A4 gene [p.G50E] in a Sri Lankan child with clinical and laboratory findings suggestive of the diagnosis of GSD
Ib. This is a new mutation which has not been described before in other children with GSD Ib and it appears that it is associated with very early onset neutorpaenia.

\section{ACKNOWLEDGEMENTS}

This research was funded by the University of Colombo and Asiri Surgical Hospial, Sri Lanka.

\section{COMPETING INTERESTS}

None declared.

\section{LIST OF ABBREVIATIONS}

GSD - Glycogen Storage Disease

G6PC - Glucose 6-phosphatase

G6PT - Glucose-6-Phosphate Translocase

SLC37A4 - Solute Carrier Family 37, Member 4 Gene

\section{REFERENCES}

Human Gene Mutation Database. 2011. http://www.hgmd.cf.ac.uk/ac/gene.php?gene=SLC37A4 (visited on 5 April 2011).

Veiga-da-Cunha M, Gerin I, Chen YT et al. 1998. A gene on chromosome 11q23 coding for a putative glucose-6phosphate translocase is mutated in glycogen-storage disease types Ib and Ic. Am J Hum Genet, 63, 976-983.

Visser G, Rake JP, Fernandes J et al. 2000. Neutropenia, neutrophil dysfunction, and inflammatory bowel disease in glycogen storage disease type Ib: results of the European Study on Glycogen Storage Disease type I. J Pediatr, 137, 187-191.

Weston BW, Lin JU, Muenzer J et al. 2000. Glucose-6Phosphatase Mutation G188R Confers an Atypical Glycogen Storage Disease Type 1b Phenotype. Pediatr Res, 48, 329-334.
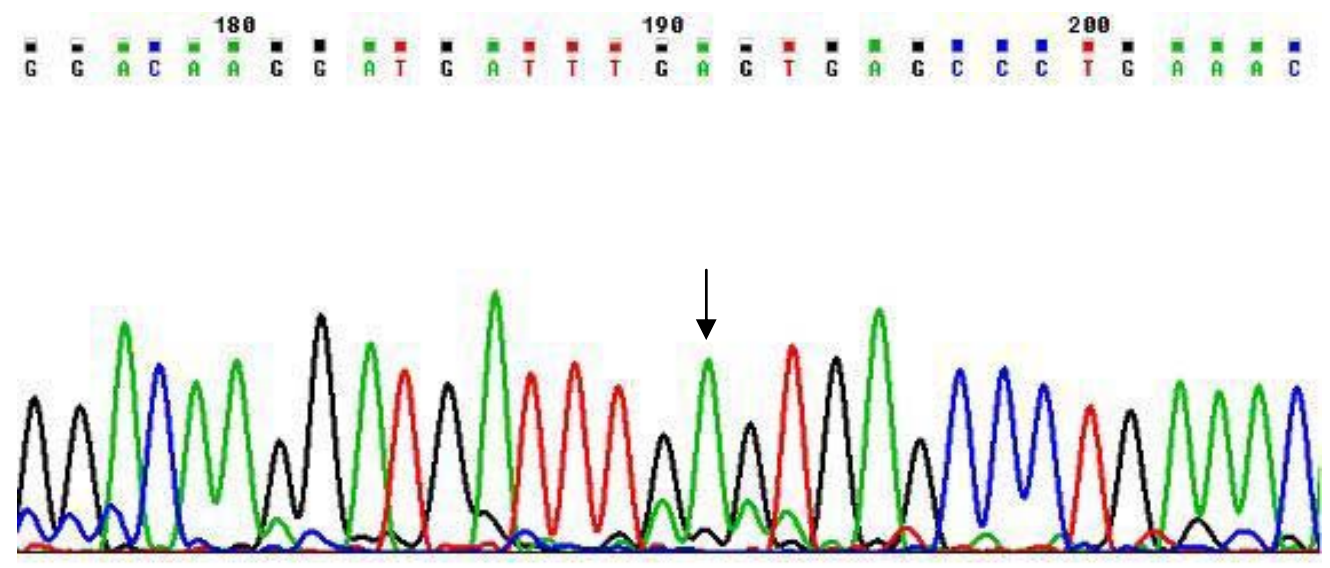

Figure 1. Electropherogram of the sense strand nucleotide sequence of the SLC37A4 gene. The arrow indicates Guanine $\rightarrow$ Adenine substitution at codon 50 in exon 1, resulting in the p.G50E missense mutation. 